\section{JURNAL LAMPUHYANG \\ LEMBAGA PENJAMINAN MUTU \\ STKIP AGAMA HINDU AMLAPURA \\ Volume 13 Nomor 1 Januari 2022 \\ p-ISSN: 2087-0760; e-ISSN: 2745-5661 \\ https://e-journal.stkip-amlapura.ac.id}

\title{
Kedwibahasaan dalam Keluarga Perkawinan Campur pada Etnik Hindu di Bali
}

\author{
Kade Restika Dewi ${ }^{1)}$, I Gusti Ngurah Wahyu Bawa Saputra ${ }^{2)}$ \\ 1,2STKIP Agama Hindu Amlapura \\ restika@stkip-amlapura.ac.id
}

\begin{tabular}{|l|l|l}
\hline Direvisi: 22 November 2021 & Diterima: 24 Desember 2021 & Diterbitkan: 1 Januari 2022 \\
\hline
\end{tabular}

\begin{abstract}
Abstrak: Penelitian kualitatif dengan pendekatan sosiolinguistik ini bertujuan untuk (1) mendeskripsikan bentuk kedwibahasaan dalam keluarga kawin campur pada etnik Hindu di Bali; (2) mendeskripsikan dominasi penggunaan bahasa (bilingual) dalam keluarga kawin campur pada etnik Hindu di Bali; (3) mendeskripsikan dampak penggunaan bilingual dlm keluarga kawin campur pd etnik Hindu di Bali; (4) mendeskripsikan faktor apa saja yang memengaruhi penggunaan bilingual dalam keluarga kawin campur pada etnik Hindu di Bali. Subjek penelitian ini adalah 3 (tiga) pasang keluarga perkawinan campur etnik Hindu Bali dan Warga Negara Asing (WNA). Data dikumpulkan dengan menggunakan metode wawancara dan observasi. Berdasarkan hasil anaalisis data ditemukan bahwa (1) Bentuk kedwibahasaan dalam keluarga kawin campur pada etnik Hindu di Bali yaitu campur kode dan alih kode; (2) Dominasi penggunaan bahasa (bilingual) dalam keluarga kawin campur pada etnik Hindu di Bali yaitu Bahasa Inggris; (3) Dampak penggunaan bilingual dlm keluarga kawin campur pada etnik Hindu di Bali yaitu dampak edukatif, sosial dan budaya; dan (4) Faktor yang memengaruhi penggunaan dwibahasa dalam keluarga kawin campur pada etnik Hindu di Bali yaitu penutur, lawan tutur, ingin menjelaskan maksud tertentu, situasi dan menjalin keakraban. Kata Kunci: Kedwibahasaan, Perkawinan Campur, Etnik Hindu
\end{abstract}

Abstract: This research is a qualitative research using a sociolinguistic approach. This study aims to (1) describe the form of bilingualism in mixed-married families in ethnic Hindus in Bali; (2) describe the dominance of language use (bilingual) in intermarried families in ethnic Hindus in Bali; (3) describe the impact of using bilingualism in mixed-married families on ethnic Hindus in Bali; (4) describe what factors influence the use of bilingualism in mixedmarried families in ethnic Hindus in Bali. The subjects of this study were 3 (three) pairs of Balinese Hindu mixed marriage families and foreign citizens (WNA). Data were collected using interview and observation methods. Based on the results of data analysis, it was found that (1) the forms of bilingualism in mixed-married families in ethnic Hindus in Bali are codemixing and code-switching; (2) The dominance of the use of language (bilingual) in intermarried families in Balinese Hindus, namely English; (3) The impact of the use of bilingualism in mixed marriage families on ethnic Hindus in Bali, namely educational, social and cultural impacts; and (4) Factors influencing the use of bilingualism in intermarried families in ethnic Hindus in Bali, namely speakers, interlocutors, wanting to explain certain intentions, situations and establishing intimacy.

Keywords: Bilingualism, Mixed Marriage, Hindu Ethnicity 


\section{PENDAHULUAN}

1.1. Latar belakang

Bali adalah pulau kecil di Indonesia yang terkenal di mata dunia. Bali dikenal dengan sebutan surga dunia (paradise of the world). Tidak hanya wisatawan domestik, wisatawan mancanegara juga berbondong-bondong datang untuk menikmati keindahan di pulau ini. Keindahan alam pulau dewata ini menjadi salah satu daya tarik bagi wisatawan untuk berkunjung dan menghabiskan waktu di pulau ini. Pantai pasir putih di Kuta, danau Batur di Kintamani, pegunungan (Gunung Agung, Gunung Batur dan Gunung Abang), daerah persawahan hijau di Tegalalang, mampu menyihir wisatawan untuk tinggal berlama-lama di pulau seribu pura ini.

Dinamika pariwisata di Bali tentunya menuntut interaksi sosial antara penduduk asli dan wisatawan ataupun pendatang. Faktanya, banyak penduduk etnik Hindu di Bali yang akhirnya menikah dengan pendatang (etnik nonHindu Bali). Perkawinan ini disebut perkawinan campur.

Perkawinan campur tentu berbeda dengan perkawinan sesama etnis. Dalam perkawinan ini tentu terdapat perbedaan-perbedaan diantara kedua etnis, seperti perbedaan kebiasaan, pola pikir, bahasa dan lainlain. Sebuah keluarga perkawinan campur harus berusaha lebih keras dalam menangani perbedaan, saling menghormati dan memahami satu sama lain agar selalu harmonis.

Kondisi kebahasaan pada keluarga perkawinan campur bisa mengalami kedwibahasaan (bilingualism) bahkan multibahasa (multilingualism). Peristiwa tersebut diakibatkan oleh adanya kontak bahasa secara intensif dalam keluarga tersbut. Keluarga perkawinan campur memiliki kemampuan Bahasa yang berbeda-beda antara istri, suami, dan anak. Masingmasing dari mereka, terutama suami atau istri, memiliki kemampuan Bahasa dari Bahasa induk atau Bahasa ibu mereka dan Bahasa kedua yang didapat dari lingkungan sosial yang baru.

Hal yang paling menarik untuk diteliti dalam perkawinan campur ini adalah terkait kedwibahasaan yang terjadi dalam keluarga tersebut, termasuk bentuk kedwibahasaannya, dominasi penggunaan bahasanya, dampaknya terhadap etnik Hindu di Bali, serta faktor yang mempengaruhi kedwibahasaan dalam keluarga tersebut. Untuk itu penelitian yang berjudul, 
"Kedwibahasaan dalam Keluarga

Perkawinan Campur pada Etnik Hindu di

Bali” menarik untuk dilakukan.

Penelitian tentang Penggunaan

Bahasa pada Keluarga Kawin Campur

sudah pernah dilakukan. Misalnya

penelitian yang berjudul Penggunaan

Bahasa pada Keluarga Kawin Campur di

Desa Tri Rukun Kecamatan Wonosari yang dilakukan oleh Ni Kadek Erawati pada tahun 2016. Penelitian tersbut bertujuan untuk mendeskripsikan pilihan bahasa, variasi bahasa serta peristiwa bahasa yang terjadi pada keluarga kawin campur di Desa Tri Rukun Kecamatan Wonosari. Hasil penelitian tersebut menunjukkan bahwa pilihan bahasa pada keluarga kawin campur di desa Tri Rukun Kecamatan Wonosari adalah Bahasa Indonesia dan Bahasa Bali (untuk keluarga Bali-Bugis), Bahasa Jawa dan Bahasa Bali (untuk keluarga Bali-Jawa), Bahasa Indonesia, Bahasa Bali dan Bahasa Melayu dialek Manado (Untuk keluarga Bali-Minahasa), Bahasa Indonesia dan Bahasa Bali (untuk keluarga Bali-Gorontalo), Bahasa Indonesia dan bahasa Melayu dialek Manado (untuk keluarga GorontaloMinahasa), dan Bahasa Indonesia dan Bahasa Melayu dialek Manado (untuk keluarga Jawa-Gorontalo).
Selain itu, penelitian tentang penggunaan Bahasa Bali dalam perkawinan campur juga pernah dilakukan pada tahun 2016 oleh Ni Luh Merita Sari. Penelitian itu berjudul Penggunaan Bahasa Bali dalam Keluarga Perkawin Campur Bali-Jawa di Kelurahan Kerobokan Kelod, Kecamatan Kuta Utara, Kabupaten Badung. Penelitian ini bertujuan untuk mendeskripsikan penggunaan Bahasa bali dalam Keluarga Perkawin Campur Bali-Jawa di Kelurahan Kerobokan Kelod dan mendeskripsikan factorfaktor yang menyebabkan Bahasa Bali bisa tetap bertahan dalam keluarga kawin campur Bali-Jawa tersebut. Berdasarkan hasil analisis dat, dapat disimpulkan bahwa penggunaan Bahasa Bali dalam keluarga kawin campur BaliJawa mencapai presentase keseluruhan terbesar dibandingkan dengan penggunaan Bahasa Indonesia dan Bahasa Jawa yakni sebesar 94,4\% dengan rincian yaitu, 1) penggunaan Bahasa Bali asli sebesar $76,6 \%$ dan 2) penggunaan Bahasa Bali dicampur dengan Bahasa Indonesia sebesar 17,8\%. Serta ditemukan bahwa factor-faktor yang menyebabkan Bahasa bali mampu bertahan dan digunakan dalam keluarga kawin campur Bali-Jawa di kelurahan 
Kerobokan Kelod, yaitu 1) kesetiaan terhadap Bahasa Bali, 2) kebanggaan terhadap Bahasa Bali, 3) kesadaran adanya norma Bahasa Bali, 4) Lingkungan masyarakat Bali, dan 5) adat masyarakat Bali.

Berdasarkan uraian diatas, dapat dilihat bahwa penelitian ini berbeda dari penelitian-penelitian sebelumnya. Penelitian seperti ini belum pernah dilakukan. Perbedaannya terletak pada fokus penelitian. Penelitian sebelumnya berfokus pada penggunaan Bahasa pada perkawinan campur antar etnik di Indonesia. Namun dalam penelitian ini fokusnya adalah kedwibahasaan dalam perkawinan campur etnik Hindu Bali dengan negara luar (terutama negara-negara yang menggunakan Bahasa Inggris sebagai Bahasa pertama atau kedua) yang tinggal di Bali.

\subsection{Rumusan Masalah}

Masalah yang akan dikaji dalam penelitian ini adalah sebagai berikut.

1. Bagaimanakah bentuk kedwibahasaan dalam keluarga kawin campur pada etnik Hindu di Bali?

2. Bagaimanakah dominasi penggunaan bahasa (bilingual) dalam keluarga kawin campur pada etnik Hindu di Bali?

3. Apa dampak penggunaan bilingual dalam keluarga kawin campur pada etnik Hindu di Bali?

4. Faktor apa saja yang memengaruhi penggunaan bilingual dalam keluarga kawin campur pada etnik Hindu di Bali?

\subsection{Tujuan Penelitian}

Sejalan dengan rumusan masalah tersebut, tujuan yang ingin dicapai dalam penelitian ini adalah sebagai berikut:

1. Untuk mendeskripsikan bentuk kedwibahasaan dalam keluarga kawin campur pada etnik Hindu di Bali.

2. Untuk mendeskripsikan dominasi penggunaan bahasa (bilingual) dalam keluarga kawin campur pada etnik Hindu di Bali.

3. Untuk mendeskripsikan dampak penggunaan bilingual $\mathrm{dlm}$ keluarga kawin campur pd etnik Hindu di Bali.

4. Untuk mendeskripsikan faktor apa saja yang memengaruhi penggunaan bilingual dalam keluarga kawin campur pada etnik Hindu di Bali. 


\subsection{Manfaat Penelitian}

Hasil penelitian ini diharapkan dapat memberikan manfaat baik secara teoretis dan praktis. Manfaat teoretis dan manfaat praktis dari hasil penelitian ini sebagai berikut.

\subsubsection{Manfaat Teoretis}

Secara teoretis, hasil penelitian ini dapat memberikan manfaat, yakni sebagai bahan rujukan atau referensi dalam pengembangan pengetahuan yang berkaitan dengan penggunaan Bahasa dalam keluarga kawin campur pada etnik Hindu di Bali.

\subsubsection{Manfaat Praktis}

Secara praktis, hasil penelitian ini nantinya dapat dimanfaatkan oleh umat Hindu, dosen Pendidikan Agama Hindu, dan peneliti lain.

\section{TINJAUAN PUSTAKA}

\subsection{Kedwibahasaan}

Kedwibahasaan merupakan salah
satu topik yang dikaji dalam
sosiolinguistik dengan fenomena
kebahasaan yang ada di dalam
masyarakat.
merupakan akibat dari kontak bahasa
antara kelompok masyarakat yang
berbahasa minoritas dengan
kelompok masyarakat yang berbahasa
mayoritas. Bloomfield (dalam Chaer,

1994:65) menjelaskan bahwa bilingual merupakan kemampuan seseorang menguasai dua bahasa sama baiknya. Berdasarkan pendapat Weinrich (dalam Chaer, 1994:65) bilingualisme merupakan penggunaan dua bahasa oleh seseorang secara bergantian. Bilingualisme dalam bahasa Indonesia disebut kedwibahasaan Chaer (2004:84). Dari istilah yang dikemukakan oleh Chaer, dapat dipahami bahwa bilingualisme atau kedwibahasaan berkenaan dengan pemakaian dua bahasa secara bergantian oleh seorang penutur dalam aktivitasnya sehari-hari atau interaksi sosialnya.

Menurut Robert Lado (1964:214) kedwibahasaan merupakan kemampuan berbicara menggunakan dua bahasa dengan sama atau hampir sama baiknya. Secara teknis pendapat ini mengacu pada pengetahuan dua bahasa oleh seseorang bagaimanapun tingkatnya. Haugen (1968:10) pendapat Lado diperkuat oleh Haugen yang menyatakan bahwa kedwibahasaan adalah mengetahui dua bahasa. Jika diuraikan lebih umum maka pengertian kedwibahasaan adalah penggunaan dua bahasa baik secara produktif maupun secara reseptif oleh seorang individu ataupun masyarakat. Haugen mengemukakan kedwibahasaan 
dengan mengetahui dua bahasa "knowledge of two languages" cukup mengetahui dua bahasa secara pasif atau “understanding without speaking”.

Kedwibahasaan

menurut

Mackey dan Fishman (Chaer \& Agustina, 2004:84) menyatakan bahwa kedwibahasaan diartikan sebagai penggunaan dua bahasa oleh seorang penutur dalam pergaulannya dengan orang lain secara bergantian. Maka dari itu, penggunaan lebih dari satu bahasa penutur harus dapat menguasai bahasa tersebut.

\subsection{Campur Kode}

1) Alih Kode

Alih kode merupakan salah satu kajian dalam bidang sosiolinguistik. Menurut Myres dan Scotton (Piantari dkk, 2011: 13) alih kode adalah peralihan penggunaan kode satu ke kode bahasa yang lainnya, sedangkan campur kode adalah penggunaan satuan bahasa dari satu bahasa ke bahasa lain untuk memperluas gaya bahasa atau ragam bahasa, termasuk di dalamnya pemakaian kata, frasa, klausa, idiom, dan sapaan.

Alih kode menurut Suwandi (2010: 86) dapat terjadi dalam sebuah percakapan ketika seorang pembicara menggunakan sebuah bahasa dan mitra bicaranya menjawab dengan bahasa lain. Apabila yang terjadi adalah antara bahasa asli dengan bahasa asing, maka disebut alih kode ekstern. Lebih lanjut Suwito (1985:72-74) menyebutkan faktor-faktor penyebab terjadinya alih kode; antara lain: (1) penutur; (2) lawan tutur; (3) hadirnya pe- nutur ketiga; (4) pokok pembicaraan; (5) membangkitkan rasa humor; dan (6) sekadar bergengsi.

Menurut Fisman (Chaer dan Agustina, 2010: 108) faktor penyebab terjadinya alih kode (a) penutur, (b) lawan tutur, (c) perubahan situasi, (d) perubahan dari formal ke informal atau sebaliknya, (e) perubahan topik pembicaraan. Penyebab terjadinya alih kode dapat ditelusuri melalui keterkaitan suatu pembicaraan dengan konteks dan situasi berbahasa.

2) Campur Kode

$\begin{array}{ccc}\text { Dalam } & \text { peristiwa tutur, } \\ \text { pembahasan mengenai alih kode, }\end{array}$
biasanya diikuti pula dengan pembicaraan mengenai campur kode. Peristiwa campur kode terjadi apabila seorang penutur bahasa, misalnya bahasa Indonesia memasukkan unsur- unsur bahasa daerah ataupun bahkan memasukkan unsur-unsur bahasa asing ke dalam pembicaraan bahasa 
Indonesianya tersebut. Dengan kata lain, seseorang yang berbicara dengan kode utama bahasa Indonesia yang mempunyai fungsi keotonomiannya, sedangkan kode bahasa daerah atau bahasa asing yang terlibat dalam kode utama tersebut merupakan serpihanserpihan saja tanpa fungsi atau keotonomian sebagai sebuah kode (Aslinda dan Syafyahya: 2007).

Selanjutnya berdasarkan unsurunsur kebahasaan yang terlibat di dalam campur kode, Suwito (1985: 78) membedakan campur kode menjadi beberapa macam, yakni: (1) penyisipan unsur yang berwujud kata; (2) penyisipan unsur yang berwujud frasa; (3) penyisipan unsur yang berwujud baster; (4) penyisipan unsur yang berwujud perulangan kata; penyisipan unsur yang berwujud ungkapan/ idiom; dan (6) penyisipan unsur yang berwujud klausa.

Faktor-faktor penyebab terjadinya campur kode (Suwito, 1985: 77) dapat dibedakan menjadi tiga, yaitu: (1) identifikasi peranan (ingin menjelaskan sesuatu/ maksud tertentu); (2) identifikasi ragam (karena situasi/yang ditentukan oleh bahasa di mana seorang penutur melakukan campur kode yang akan menempatkan dia dalam hierarki status sosialnya); dan (3) keinginan untuk menjelaskan dan menafsirkan (ingin menjalin keakraban penutur dan lawan tutur/menandai sikap dan hu- bungannya terhadap orang lain dan sikap serta hubungan orang lain terhadapnya).

\subsection{Kawin Campur}

Di Indonesia pada umumnya perkawinan adalah suatu hal yang dianggap suci, karena setiap kaedahkaedah yang menyangkut tentang perkawinan dihubungkan langsung dengan kaedah-kaedah agama. Di Indonesia juga terdapat perundangundanganan yang mengatur tentang perkawinan, peraturan ini dibuat untuk menghindari adanya seks bebas dan diharapkan untuk melanjutkan keturunan dengan cara yang "sah" atau yang resmi sesuai perundang-undangan.

Pasangan yang berbeda agama mengalami kesulitan dalam melaksanakan perkawinan akibat pelaksanaan UU No. 1 Tahun 1974 tentang Perkawinan yang melarang perkawinan yang dilaksanakan oleh pasangan yang berbeda agama. Hal ini menyebabkan terjadinya "penyelundupan hukum" agar perkawinan mereka diakui oleh negara. "Penyelundupan hukum" ini berupa 


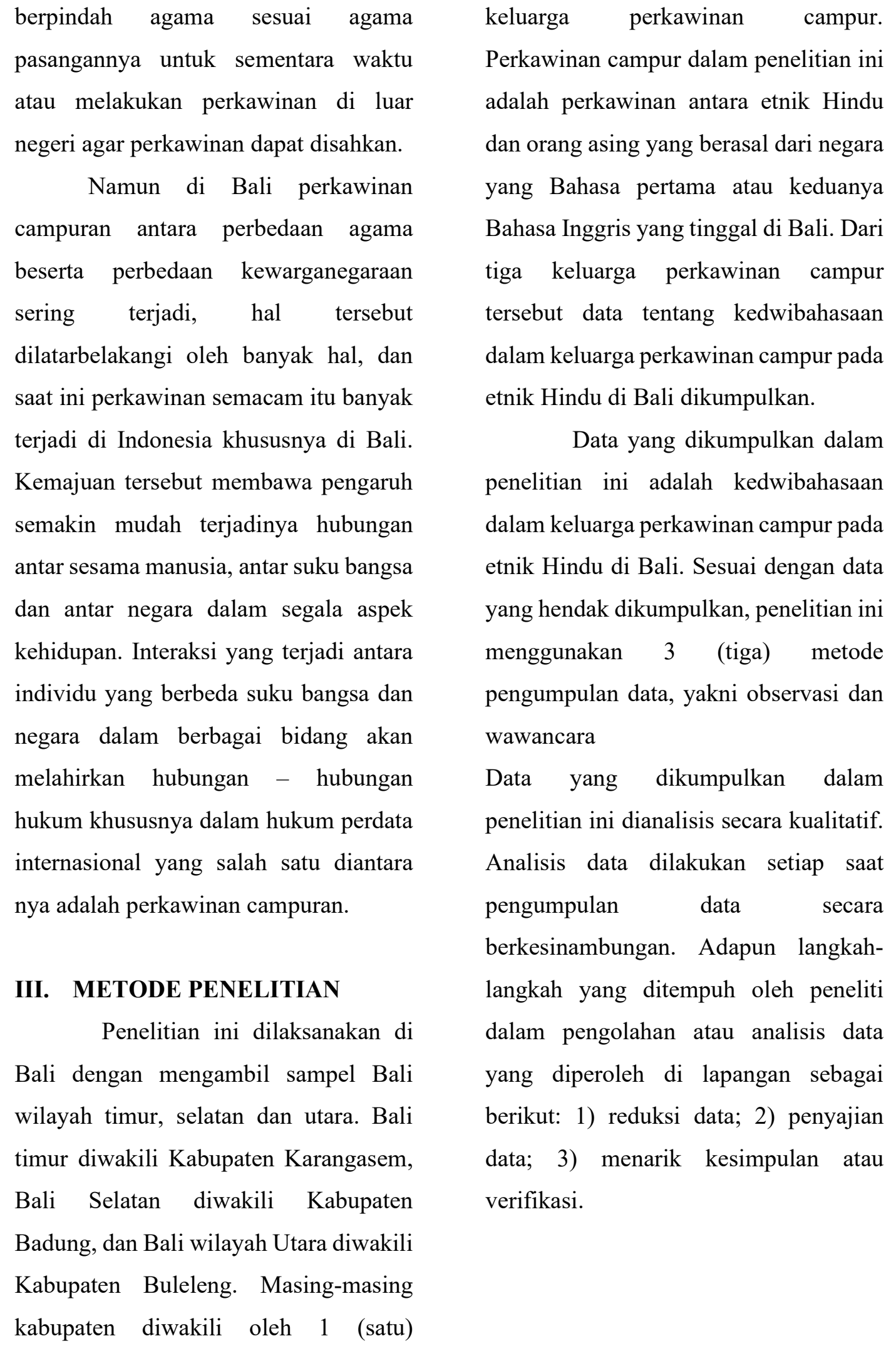




\section{HASIL DAN PEMBAHASAN}

\subsection{Hasil Penelitian}

Bentuk kedwibahasaan pada kawin campur di masing-masing daerah bervariasi. Berikut akan dideskripsikan lebih detail pada masing-masing subjek.

\subsubsection{Kedwibahasaa pada Keluarga}

Perkawin Campur di Kabupaten

Karangasem

Data terkait bentuk kedwibahasaan pada keluarga perkawinan campur didapatkan melalui wawancara dan observasi. Subjek yang berasal dari Kabupaten Karangasem terdiri atas pasangan suami isteri, yang mana sang isteri merupakan etnik Hindu dan sang suami merupakan WNA asal Australia. Mereka sudah menikah selama kurang lebih 2 (dua) tahun. Dan sang suami sudah tinggal menetap di Bali selama 3 (tiga) tahun/ setahun sebelum menikah.

Berdasarkan hasil data di lapangan diketahui bahwa bahasa yang digunakan oleh pasangan tersebut adalah campuran antara Bahasa Inggris dan Bahasa Indonesia. Dalam berkomunikasi isteri lebih cenderung mencampur unsurunsur Bahasa Inggris dan Bahasa Indonesia, namun suami tetap menjawabnya dengan Bahasa Inggris. Seperti contoh:

\author{
Dialog 1 \\ Woman : "Why you barking all \\ night? barking. When we \\ sudah wake up, she still \\ barking." \\ Man : "Eemm.." \\ Woman : "What you makan? \\ What Mikes makan?" \\ Man : "I don't know. \\ Something she found on \\ the floor. Bash no, it is \\ rubbish, what are you \\ doing? Are you spitting \\ that again haa.. and then \\ more makan." \\ Woman: "Like bug this one." \\ Man : "No it is the big one. he \\ found it."
}

Dalam percakapan yang direkam, sang suami sepenuhnya merespon isterinya dengan Bahasa Inggris, kecuali pada kata makan. Hal yang sama juga terjadi pada percakapan mereka selanjutnya.

Dalam hal ini, terlihat keterbatasan suami dalam berbahasa Indonesia, mengingat dia baru 3 (tahun) tinggal di Indonesia. Sehingga isteri akhirnya mengalah dengan mencampur Bahasa Indonesia dan Inggris dalam berbicara atau bahkan sepenuhnya menggunakan Bahasa Inggris, dengan tujuan agar mudah dimengerti oleh suami. 
4.1.2. Kedwibahasaa pada Keluarga Perkawin Campur di Kabupaten Buleleng

Pasangan perkawinan campur yang berasal dari Kabupaten Buleleng terdiri atas suami dan isteri, dimana suami merupakan WNA asal Portugis dan isteri merupakan etnik Hindu Bali asal Desa Sambangan, Buleleng. Pasangan ini menikah pada tahun 2019. Jadi kurang lebih baru 2 (dua) tahun.

Berdasarkan data yang didapatkan di lapangan, dapat diketahui bahwa Bahasa yang digunakan oleh pasangan perkawinan campur antara suami yang berkewarganegaraan Portugis dan isteri yang merupakan etnik Hindu Bali yang tinggal di Buleleng ini adalah campuran antara Bahasa Inggris dan Bahasa Indonesia. Seperti pada percakapan mereka ketika membicarakan buah-buahan.

Dialog 3

Isteri : You like or you don't like?

Suami : Enak

Isteri : $\overline{\text { Aahh. }}$

Suami : Enak

Isteri : What?

Suami : What? Enak means I don't like?

Isteri : (Ketawa) coba dong. Try, try to peel it?

Suami : I smell it

Isteri : I wanna try. It's probably, it's probably not sweet. Ngga tau. Coba! You wanna eat or you wanna play?

$$
\begin{array}{ll}
\text { Suami } & \text { : Both. I wanna play first } \\
\text { and then when this is done } & \\
& \text { I can eat. } \\
\text { Isteri } & \text { :You want me to peel? } \\
\text { Suami } & \text { :Yeah. If you want to do it. } \\
& \text { You can't wait. }
\end{array}
$$

Dalam percakapanpercakapannya yang lain juga masih ditemukan Bahasa-bahasa campuran Inggris dan Indonesia. Namun lebih banyak terlihat Bahasa Inggris yang mendominasi secara struktur kalimat dan kata, penggunaan Bahasa Indonesia hanya masuk 1 (satu) atau 2 (dua) kata dan terkadang pada ujaran pendek.

Hal tersebut terjadi dikarenakan, pasangan ini merupakan pasangan baru dimana sang suami belum bisa berbahasa Indonesia. Jadi, sang isteri mengalah denganmenggunakan Bahasa inggris, namun juga berkeinginan mengajarkan Bahasa Indonesia ke suaminya. Sehingga Bahasa yang digunakan merupakan campuran antara Bahasa inggris dan Bahasa Indonesia.

\subsubsection{Kedwibahasaa pada Keluarga Perkawin Campur di Kabupaten Badung}

Keluarga perkawinan campur yang menjadi subjek di Kabupaten Badung adalah, sepasang suami isteri 
dengan seorang anak berusia 9 tahun.

Sang suami merupakan WNA asal

Belgia dan isteri merupakan etnik Hindu

Bali. Mereka tinggal di J1. Danau

Tamblingan III no.1 Taman Griya

Jimbaran, Badung. Usia pernikahan

mereka sekitar 11 tahun, dan telah

dikarunai 1 (satu) orang anak perempuan

yang saat ini sudah berusia 9 tahun.

Berdasarkan data yang didapat

di lapangan, suami isteri dalam keluarga

perkawinan campur ini menggunakan

Bahasa Indonesia dan Bahasa Inggris

dalam berkomunikasi sehari-hari di

keluarga. Namun sang anak

menggunakan tidak hanya Bahasa

Indonesia dan Inggris tapi juga

berbahasa Bali dan Prancis. Ketika

berbicara dengan ayahnya sang anak menggunakan Bahasa Prancis atau Inggris. Sedangkan ketika berbicara dengan Ibunya, dia menggunakan Bahasa Indonesia.

Namun pada dasarnya, Bahasa yang dominan digunakan sehari-hari adalah Bahasa Inggris dan Bahasa Indonesia. Terlihat dalam percakapan yang dilakukan anak dengan ayahnya. Mereka menggunakan Bahasa Inggris.

Dialog 3

Ayah $\because:$ "So, Anak do you want that we order pizza for lunch?"

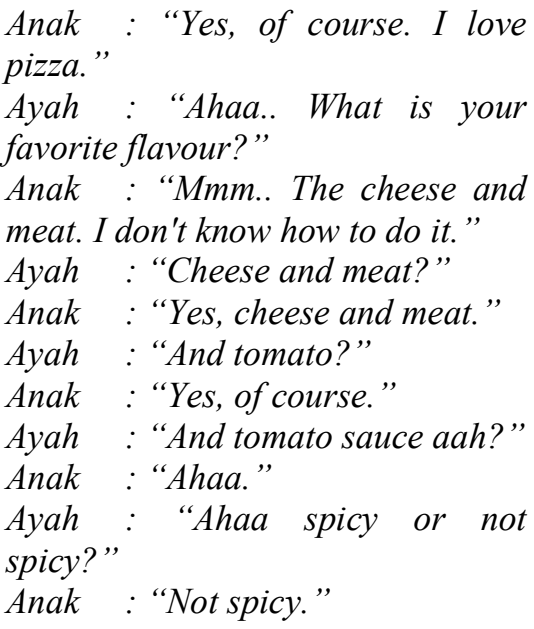

Berbeda lagi ketika si anak berkomunikasi dengan ibunya. Dia memilih menggunakan Bahasa Indonesia. Seperti dapat dilihat pada dialog di bawah ini/

Dialog 4

Anak : "Mama tadi rujaknya enak banget lo ma."

Mama : "Bener ?"

Anak : "Besok buat lagi boleh ?"

Mama : "Boleh. Rujak apa tadi jadi Anak buat?"

Anak : "Anak tadi buat rujak gula pasir."

Mama : "Mmm... Buahnya buah apa ?"

Anak : "Buahnya semua tak pake orang enak."

Mama : "Buah apa itu?"

Anak : "Buahnya ada buah mangga, timun Anak pake dikit Anak takut gak enak, habis itu bengkuang habis itu, itu aja."

Dalam percakapan tersebut terlihat bahwa si anak bisa beralih secara total menggunakan Bahasa Indonesia, berbeda ketika berbicara dengan ayahnya. Peralihan Bahasa yang 
sempurna tersebut terjadi karena konsistensi dari orang tua menggunakan Bahasa dalam berkomunikasi sehari-hari di keluarga. Berdasarkan hasil wawancara dengan orang tuanya, mereka membuat kesepakatan dalam urusan penggunaan Bahasa sang anak. Dimana, ibunya akan mengajarkan

Menurut pengakuan sang ibu, alih Bahasa yang sempurna itu terjadi ketika anak memasuki usia sekitar 4 (empat) tahun. Sebelum usia itu, sang anak sempat mencampur Bahasa Inggris dan Bahasa Indonesia ketika berkomunikasi dalam keluarga. Namun, dengan konsistensi yang dilakukan oleh kedua orang tuanya, akhirnya saat ini, saat anak ini berusia 9 (Sembilan) tahun, peralihan Bahasa terjadi secara sempurna.

Berbeda halnya dengan ayah dan ibunya. Meskipun secara dominan Bahasa yang digunakan ayah dan ibu saat berkomunikasi dalam keluarga adalah Bahasa Inggris, namun terkadang kata Bahasa Indonesia muncul. Seperti contoh dalam dialog berikut ini.

\section{Dialog 4}

Isteri : Are you busy, pa?

Suami : Nope. What? What can I help?

Isteri : Pa, please help look at kompornya at the kitchen. I think forget to turn it off.
Suami : alright.

Beberapa menit kemudian

Isteri : And please bring me something to drink ya.

Suami : What do you want? Water?juice?

Isteri : Do we have juice? Please check di kulkas ya.

Suami: We still have. Do you want?

Isteri : Sure. Give me a glass ya. Thanks.

Meskipun sang suami dan isteri ini sangat konsisten dalam menggunakan Bahasa dengan anak mereka, namun kenyataannnya saat berkomunikasi berdua, isteri sering memasukkan kata Berbahasa Indonesia dalam ujarannya.

\subsubsection{Dampak Penggunaan Dwibahasa dalam Perkawinan Campur Perkawinan campur tentu} memiliki dampak terhadap keluarga itu sendiri, khususnya dalam hal penggunaan dwibahasa. Berdasarkan data hasil wawancara, dampak penggunaan dwibahasa dalam perkawinan campur dapat dibedakan menjadi 3 (tiga) yaitu dampak sosial, budaya dan pendidikan.

1) Dampak Sosial

Penggunaan dwibahasa dalam perkawinan campur berdampak baik bagi lingkungan sosial masyarakat 
tempat keluarga perkawinan campur ini tinggal. Berdasarkan wawancara, adanya dwibahasa yang digunakan oleh keluarga perkawinan campur, membuat masyarakat sekitar menjadi bersemangat untuk belajar Bahasa Inggris.

2) Dampak Budaya

Penggunaan dwibahasa juga mempengaruhi keluarga perkawinan campur ini secara gaya hidup dan kebiasaan. Seperti hasil wawancara dari salah satu pasangan perkawinan campur ini, mereka sepakat untuk childfree atau tidak memiliki anak. Dengan demikian, dapat disimpulkan bahwa penggunaan dwibahasa dalam perkawinan campur juga mempengaruhi budaya pada keluarga tersebut.

3) Dampak edukatif

Secara edukatif, penggunaan dwibahasa dalam perkawinan campur berdampak positif. Hal tersebut dapat dilihat dari anak hasil perkawinan campur yang menggunakan dwibahasa. Anak ini terpapar dwibahasa sejak kecil, hal tersebut baik untuk perkembangan kognitif dan akademik anak ini. Terbukti dengan prestasinya di sekolah, anak ini dapat melakukan percepatan 2 tingkat. Di usianya yang baru 9 (Sembilan) tahun seharusnya dia masih kelas $3 \mathrm{SD}$, namun karena ketika kelas 1, prestasinya melebihi teman seangkatannya, sekolah melakukan tes akselerasi, dan anak ini dinyatakan memiliki kemampuan setingkat anak kelas 3. Dengan pertimbangan yang matang, akhirnya orang tuanya mengijinkan anak ini untuk melompat kelas. Perkembangan bahasanya juga sangat baik, terbukti dia bahkan mampu menguasai 4 (empat) bahasa sekaligus yaitu Bahasa Indonesia, Bali, Inggris dan Perancis. Dengan modal Bahasa internasional yang dimiliki, kelak dia akan mudah berkomunikasi dengan masyarakat internasional.

\subsubsection{Faktor yang mempengaruhi Kedwibahasaan dalam Keluarga Kawin Campur}

Berdasarkan hasil analisis data, terdapat beberapa faktor yang menyebabkan terjadinya alih kode dalam penelitian ini. Adapun faktor yang mempengaruhi penggunaan alih kode, diantaranya: 
a. Penutur

Alih kode dalam penelitian ini dilakukan oleh anak hasil perkawinan campur yang tinggal di kapupaten Badung. Alih kode terjadi dikarenakan anak ini menguasai 4 (empat) Bahasa yakni Bahasa Indonesia, Bahasa Bali, Bahasa Inggris dan Bahasa Perancis. Jadi, anak ini berbicara menggunakan Bahasa tertentu menyesuaikan dengan lawan bicaranya.

b. Lawan tutur

Seperti yang dijelaskan di atas, alih kode terjadi dikarenakan lawan bicara yang berbeda-beda. Ketika berbicara dengan ibunya, dia menggunakan Bahasa Indonesia secara penuh. Ketika berbicara dengan ayahnya, dia menggunakan Bahasa Inggris. Ketika berbicara dengan neneknya yang etnik Hindu Bali, dia menggunakan Bahasa Bali. Dan ketika berbicara dengan neneknya yang dari belgia, dia menggunakan Bahasa Perancis.
Sedangkan faktor yang menyebabkan terjadinya penggunaan campur kode dalam penelitian ini adalah:
a. Ingin menjelaskan situasi/maksud tertentu
b. Karena situasi
c. Ingin menjalin keakraban.

\subsection{Pembahasan}

Dalam penelitian ini ditemukan bahwa kedwibahasaan yang terjadi yaitu penggunaan Bahasa Indonesia dan Bahasa Inggris dalam perkawinan campur antara etnik Hindu Bali dan warga negara asing. Terlebih lagi, berdasarkan hasil observasi, anak hasil perkawinan campur ini bahkan menggunakan multibahasa yaitu Bahasa Indonesia, Bahasa Bali, Bahasa Inggris dan Bahasa Perancis.

Adapun bentuk kedwibahasaan yang terjadi, berdasarkan hasil analisis data, terdiri dari dua bentuk, yaitu alih kode dan campur kode. Menurut Myres dan Scotton (Piantari dkk. 2011: 13) alih kode adalah peralihan penggunaan kode satu ke kode bahasa yang lainnya, sedangkan campur kode adalah penggunaan satuan bahasa dari satu bahasa ke bahasa lain untuk memperluas gaya bahasa atau ragam bahasa, termasuk di dalamnya pemakaian kata, 
frasa, klausa, idiom, dan sapaan (Kridalaksana, 2008: 40).

Alih kode terjadi pada anak hasil perkawinan campur dari pasangan yang tinggal di kabupaten badung. Ketika berbicara dengan ibunya, anak ini menggunakan Bahasa Indonesia. Kemudian dia akan beralih menggunakan Bahasa Inggris ketika berbicara dengan ayahnya. Bahasa Bali dia gunakan ketika berkomunikasi dengan nenek dan kakeknya, yang merupakan etnik Hindu Bali, sedangkan Bahasa Perancis dia gunakan ketika berbicara dengan nenek kakeknya dari Belgia.

Campur kode terjadi pada setiap pasangan kawin campur yang terlibat dalam penelitian ini. Campur kode yang terjadi yaitu berupa kata dan frasa bahasa Indonesia yang dicampur dengan Bahasa Inggris. Jadi secara umum, Bahasa yang dominan digunakan dalam komunikasi sehari-hari mereka adalah Bahasa Inggris.

Alih kode ataupun campur kode yang terjadi dalam komunikasi pasangan kawin campur tersebut tentu saja memiliki dampak. Adapun dampak yang ditimbulkan berdasarkan hasil penelitian ini adalah dampak sosial, dampak budaya, dan dampak edukatif.
Dampak sosial terjadi yaitu adanya dwibahasa yang digunakan oleh keluarga perkawinan campur, membuat masyarakat sekitar menjadi bersemangat untuk belajar Bahasa Inggris. Hal tersebut menjadi motivasi sendiri bagi masyarakat agar mampu berkomunikasi dengan Bahasa Inggris. Berdasarkan pernyataan tersebut, dapat dikatakan bahwa penggunaan dwibahasa dalam perkawinan campur berdampak positif bagi masyarakat.

Dampak Budaya dapat dilihat dari perubahan gaya hidup dan kebiasaan pasangan perkawinan campur tersebut. Seperti hasil wawancara dari salah satu pasangan perkawinan campur ini, mereka sepakat untuk childfree atau tidak memiliki anak. Hal seperti ini tentunya sangat tidak lumbrah di Indonesia, khususnya bagi umat Hindu di Bali, dimana kita tahu bahwa tujuan menikah bagi umat Hindu Bali adalah untuk memperoleh keturunan yang akan meneruskan silsilah keluarga. Namun, keluarga perkawinan campur ini tidak menginginkan hal tersebut. Perempuan etnik Hindu pada pasangan perkawinan campur ini, dengan percaya diri berpakaian terbuka dalam kesehariannya. Dan setiap bulan selalu menyempatkan diri untuk berlibur 
bersama keluarga. Hal tersebut juga tidak lumbrah di budaya kita di Bali. Dengan demikian, dapat disimpulkan bahwa penggunaan dwibahasa dalam perkawinan campur juga mempengaruhi budaya pada keluarga tersebut.

Dan yang terakhir, dampak edukatif dapat dilihat dari anak hasil perkawinan campur yang menggunakan dwibahasa. Anak ini terpapar dwibahasa sejak kecil, hal tersebut baik untuk perkembangan kognitif dan akademik anak ini. Terbukti dengan prestasinya di sekolah, anak ini dapat melakukan percepatan 2 tingkat. Di usianya yang baru 9 (Sembilan) tahun seharusnya dia masih kelas $3 \mathrm{SD}$, namun karena ketika kelas 1, prestasinya melebihi teman seangkatannya, sekolah melakukan tes akselerasi, dan anak ini dinyatakan memiliki kemampuan setingkat anak kelas 3. Dengan pertimbangan yang matang, akhirnya orang tuanya mengijinkan anak ini untuk melompat kelas. Perkembangan bahasanya juga sangat baik, terbukti dia bahkan mampu menguasai 4 (empat) bahasa sekaligus yaitu Bahasa Indonesia, Bali, Inggris dan Perancis. Dengan modal Bahasa internasional yang dimiliki, kelak dia akan mudah berkomunikasi dengan masyarakat internasional. Selain itu, para suami berkewarganegaraan asing dalam perkawinan campur ini juga termotivasi untuk belajar berbahasa Indonesia dikarenakan mereka tinggal di Bali. Sehingga nantinya mereka mudah berkomunikasi dengan lingkungan sekitar dan mudah mempelajari kebudayaan daerah Bali.

\section{PENUTUP}

Berdasarkan hasil dan pembahasan tersebut, dalam penelitian ini dapat ditarik beberapa simpulan sebagai berikut.

5.1.1. Bentuk kedwibahasaan dalam keluarga kawin campur pada etnik Hindu di Bali yaitu campur kode dan alih kode.

5.1.2. Dominasi penggunaan bahasa (bilingual) dalam keluarga kawin campur pada etnik Hindu di Bali yaitu Bahasa Inggris.

5.1.3. Dampak penggunaan bilingual dlm keluarga kawin campur pada etnik Hindu di Bali yaitu dampak edukatif, sosial dan budaya.

5.1.4. Faktor yang memengaruhi penggunaan dwibahasa dalam keluarga kawin campur pada etnik Hindu di Bali yaitu penutur, lawan tutur, ingin menjelaskan 
maksud tertentu, situasi dan menjalin keakraban.

Oleh karena itu, bagi umat Hindu di Bali, khususnya yang melakukan kawin campur disarankan tetap menggunakan Bahasa Indonesia ataupun Bahasa Bali dalam komunikasi di keluarga. Bahasa merupakan hal yang tak terpisahkan dari budaya. Untuk mewariskan budaya, bahasa memegang peranan penting. Menggunakan dwibahasa dalam keluarga merupakan hal yang bijak untuk diterapkan.

Dosen pendidikan Bahasa Inggris di lingkungan perguruan tinggi Hindu, hendaknya lebih banyak melakukan edukasi khususnya berkaitan dengan kajian sosiolinguistik, sehingga masyarakat Hindu yang hendak melakukan kawin campur memiliki dasar pijakan terutama berkaitan dengan Bahasa yang akan digunakan dalam keluarganya.

Peneliti lain disarankan untuk melakukan penelitian sejenis agar memperkaya khasanah tentang kedwibahasaan dalam keluarga Hindu.

\section{DAFTAR PUSTAKA}

Arifin, Bustanul dan Abdul, Rani. 2000. Prinsip-Prinsip Analisis Wacana.
Jakarta: Departemen Pendidikan Nasional.

Aslinda dan Leni Syafyahya. 2007. Pengantar Sosiolinguistik. Bandung: PT Refika Aditama.

Chaer, Abdullah dan Leoni, Agustina. 2010. Sosiolinguistik. Jakarta: Rineka Cipta.

Kridalaksana, Harimurti. 2008. Kamus Linguistik. Jakarta: Gramesia pustaka.

Nababan. 1984. Sosiolinguistik Suatu Pengantar. Jakarta: PT. Gramedia Jakarta.

Ohoiwutun, Paul. 1997. Sosiolinguistik: Memahami Bahasa dalam Konteks Masyarakat dan Kebudayaan. Terjemahan oleh Herman Sudrajat. Jakarta: Kesaint Blanc.

Padmadewi, dkk. 2014. Sosiolinguistik. Yogyakarta: Graha Ilmu.

Soepomo. (2000). Tentang Hukum Adat. Jakarta: PT.Pradyana Paramita.

Suandi, I Nengah. 2014.

Sosiolinguistik. Yogyakarta: Graha Ilmu.

Sudiatmaka, K., Adnyani, N. K. S., \& Windari, R. A. (2016). Putusan MUDP Bali No.01/Kep/PSM3MDP Bali $/ \mathrm{X} / 2010$ Sebagai Legitimasi Formal Anak Perempuan Berhak Mewaris di Kabupat- en Buleleng. In Seminar Nasional Riset Inovatif. Sanur, Bali: Undiksha Press.

Suwito, 1983. Pengantar Awal Sosiolinguistik Teori dan Problema. Surakarta UNS Perss.

Suwito. 1983. Sosiolinguistik

Pengantar Utama. Surakarta: Universitas Sebelas Maret.

Suwito. 1982. Pengantar Awal Sosiolinguistik: Teori dan Problema. Surakarta: Henary Offset Surakarta. 